\begin{tabular}{|c|l|}
\hline Title & Evaluation of drag coefficients of poplar-tree crowns by a field test method \\
\hline Author(s) & Koizumi, A kio; Motoyama, Jun-ichi; Sawata, Kei; Sasaki, Yoshihisa; Hirai, Takuro \\
\hline Citation & Journal of Wood Science, 56(3), 189-193 \\
https://doi.org/10.1007/310086-009-1091-8 \\
\hline Issue Date & 2010-06 \\
\hline Doc URL & http://hdl.handle.net/2115/43135 \\
\hline Rights & The original publication is available at www.springerlink.com \\
\hline Type & article (author version) \\
\hline File Information & koizumi.pdf \\
\hline
\end{tabular}

Instructions for use 


\title{
Evaluation of drag coefficients of poplar-tree crowns by a field test method
}

\author{
by
}

Akio Koizumi, Jun-ichi Motoyama, Kei Sawata, Yoshihisa Sasaki, and Takuro Hirai

Graduate school of Agriculture, Hokkaido University

\section{Key words}

Drag coefficient, Poplar tree crown, Windthrow resistance, Field test method

\begin{abstract}
To estimate the wind force that causes windthrow damage to a tree, the drag coefficients of actual-sized trees were evaluated by a field test method. In this method, the wind velocity and stem deflection were monitored simultaneously. The wind force acting on a tree crown was calculated from the stem deflection; the stem stiffness was evaluated by conducting tree-bending tests. The results of tests conducted on three poplar trees showed that the drag coefficients decreased with an increase in the wind velocity. Although the variation in the drag coefficients was large at low wind velocity because of the vibrating behavior of the stem subjected to variable wind force, the variation at wind velocities above $10 \mathrm{~m} / \mathrm{s}$ was small. The average drag coefficient at a wind velocity of $30 \mathrm{~m} / \mathrm{s}$ was estimated by the curve fitting of a power function to the wind velocity-drag coefficient relationship, and it was found to be 0.102 , which was smaller than that of actual-sized conifers studied in previous wind tunnel experiments. The drag coefficients of these crown areas in the defoliation season were smaller than those measured in the leaved season.
\end{abstract}

\section{Introduction}

Windthrow damages to trees in plantation forests and along roadsides in urban districts have caused enormous economic loss and danger involving human lives ${ }^{1}$. In order to predict wind damage to trees, such as stem breaking or uprooting, it is essential to quantitatively estimate the wind force acting on a tree crown. Drag coefficient of a tree crown $\left(C_{\mathrm{D}}\right)$ defined in Eq. 1, which is necessary to estimate wind force $\left(P_{\mathrm{w}}\right)$, have been evaluated from wind tunnel studies ${ }^{2-7}$.

$$
P_{\mathrm{W}}=\frac{1}{2} C_{\mathrm{D}} \rho A U^{2}
$$

Where $\rho$, the air density $\left(1.20 \mathrm{~kg} / \mathrm{m}^{3}\right) ; A$, the horizontally projected crown area; $U$, the wind velocity.

Most of the specimens used for the wind tunnel studies were dwarf potted trees or small 
models because of the restriction of the wind tunnel size. However, with regard to the wind-force response, it is noteworthy that the similarity rule is not applicable to the relationship between dwarf trees and actual trees. In fact, the drag coefficients of small trees at a wind velocity of $10 \mathrm{~m} / \mathrm{s}$ were found to be $0.95-1.35^{4}, 0.75-0.95^{5}$, and $1.00{ }^{6}$, and these values were considerably greater than those of actual-sized trees ${ }^{3}$, i.e., $0.29-0.88$. These actual-sized specimens were coniferous species for plantations. The drag coefficients of actual-sized broadleaf species have not yet been obtained. These $C_{\mathrm{D}}$ values are necessary for the wind break assessment for park trees or roadside trees.

The aim of this study is to develop a test method to evaluate $C_{\mathrm{D}}$ of actual-sized trees in the field which is more convenient method compared with wind tunnel experiments. In this paper, the drag coefficients of actual-sized poplar trees were evaluated by the proposed field test method that involved monitoring the wind velocity and stem deflection simultaneously.

\section{Materials and methods}

\section{Sample trees}

Three trees were sampled from the east-west row of black poplars (Populus nigra var. italica) planted in 2000 in the Hokkaido University Campus. The south side of the row of trees was an open space without any buildings, and the prevailing wind direction was south. The dimensions of two of the sample trees (tree nos.1 and 2) were measured in October 2007 and those of tree no. 3 were measured in October 2008 (Table 1).

\section{Field tests}

The wind velocity and stem deflection of the sample trees were monitored simultaneously (Fig. 1). The north-south and east-west components of the wind velocity $(U)$ were monitored using an ultrasonic anemometer (Young Company, Model 85000) by placing it near each sample tree. The height of the anemometer was adjusted with respect to the height of the wind pressure center $\left(H_{\mathrm{W}}\right)$ (Eq. 2$)$, which corresponds to the center of gravity of the crown; a crown was considered to be an ellipse whose major and minor axes are the length and breadth of the crown, respectively.

$$
H_{\mathrm{w}}=H_{\mathrm{C}}+\frac{1}{2} L_{\mathrm{C}}
$$

where $H_{\mathrm{C}}$ is the height of the crown base and $L_{\mathrm{C}}$ is the length of the crown.

Stem deflections were measured using a self-made middle-ordinate gauge ${ }^{8}$, both ends of which were screwed into a stem at a height of 115-165 cm. A deflection sensor (Kyowa Dengyo, DTH-A-5) was set at the center of the gauge span $(s=500 \mathrm{~mm})$. The wind velocity 
and stem deflections $(\delta)$ were measured along both the north-south and the east-west orientations and recorded in a data logger at $10-\mathrm{Hz}$ intervals. The measurements were performed on windy days in both leaved and defoliation seasons; the measurement results are listed in Table 2. The measured data were divided into 1-h intervals, and data for $389 \mathrm{~h}$, which included those measured at wind velocities above $5 \mathrm{~m} / \mathrm{s}$, were analyzed.

In order to measure the stiffness of the tree stems, bending tests of the sample trees were conducted once on calm days in each measurement period. A bending moment below the elastic limit was applied by pulling the stem from the north and east directions using a hand winch. The applied force was measured using a load cell connected between the sling, which was tied to the stem, and the hand winch, and it was recorded in the data logger. From the elastic relationship between the moment applied at the middle-ordinate gauge $\left(M_{\mathrm{L}}\right)$ and the stem deflection $(\delta)$, the stem stiffness $(K)$ was determined for both the north-south and the east-west orientations.

$$
K=\frac{M_{\mathrm{L}}}{\delta}
$$

After the bending tests, the natural periods of the sample trees were determined from the free-swaying movements of the stems.

\section{Calculation of $C_{\mathrm{D}}$}

The wind force acting on a crown $\left(P_{\mathrm{w}}\right)$ was calculated from Eq. 4.

$$
P_{\mathrm{w}}=\frac{K \delta}{\left(H_{\mathrm{w}}-H_{\mathrm{D}}\right)}
$$

where $H_{\mathrm{D}}$ is the height of the deflection sensor (Fig. 1).

Then, $C_{\mathrm{D}}$ was calculated every second from the ratio of $P_{\mathrm{W}}$ to $U^{2}$ using Eq. $1 . \quad C_{\mathrm{D}}$ of the north-south component was analyzed because the east-west component was rather small and it might have been disturbed by the adjacent trees.

\section{Results and discussion}

\section{Shapes of tree crowns}

The actual areas and heights of the centers of gravity of the sample tree crowns were obtained by binarizing their photographs (Fig. 2). The actual areas of the crowns were found to be smaller than those obtained by assuming an ellipsoidal shape by $19-27 \%$ and greater than 
those obtained by assuming a triangular shape, as is the case with conifers ${ }^{3}$, by $15-27 \%$. The heights of the centers of gravity were estimated to be $47-48 \%$ of $L_{C}$ from the crown base. In this study, the projected frontal area of the crowns was assumed to be an ellipsoid. This assumption was also used for calculating $C_{\mathrm{D}}$ of defoliated crowns.

The effect of the wind force acting on the stem below a crown was neglected because of the small area of the stem as compared to that of the crown, slow wind velocity near the ground level, and short distance between the wind-pressure center of a stem and the height of the middle-ordinate gauge $\left(H_{\mathrm{D}}\right)$.

\section{Relationship between wind velocity and $C_{\mathrm{D}}$}

The stem deflections showed positive relationship with wind velocity as shown in Fig. 3 . The average $C_{\mathrm{D}}$ calculated from this relationship decreased with an increase in the wind velocity (Fig. 4). This decrease in $C_{\mathrm{D}}$ can be explained by the decrease in the projected area of the crowns because of the swaying movement of leaves and branches, as observed in a wind tunnel study ${ }^{3}$. The variation in $C_{\mathrm{D}}$ was found to be large at a low wind velocity. This could be explained by the vibrating behavior of a stem subjected to a variable wind force; fine fluctuations were observed in stem deflection (Fig. 3). The variation in $C_{\mathrm{D}}$ was small at wind velocities above $10 \mathrm{~m} / \mathrm{s}$. In order to reduce the effect of vibrations at low wind velocities such as $5 \mathrm{~m} / \mathrm{s}, C_{\mathrm{D}} \mathrm{S}$ were calculated by generating moving averages from 1 to $10 \mathrm{~s}$; this range includes the natural periods of the sample trees (2.8 to $3.7 \mathrm{~s}$ ) (Fig. 5). However, no significant change was found in standard deviations as well as the average $C_{\mathrm{D}}$.

The average $C_{\mathrm{D}}$ was calculated at wind velocity intervals of $0.5 \mathrm{~m} / \mathrm{s}$ using all data for each measurement period (Fig. 6). $C_{\mathrm{D}}$ decreased with the wind velocity, as discussed before. The average $C_{\mathrm{D}}$ of the leaved crowns at a wind velocity of $10 \mathrm{~m} / \mathrm{s}$ was 0.250 .

\section{Comparison between $C_{\mathrm{D}}$ values of poplars and conifers}

Because wind velocity above $30 \mathrm{~m} / \mathrm{s}$ is assumed as a maximum possible velocity and is considered in building design in urban areas, critical wind velocity could also be assumed as $30 \mathrm{~m} / \mathrm{s}$ concerning wind resistance of roadside trees ${ }^{6}$. In order to estimate $C_{\mathrm{D}}$ at the wind velocity of $30 \mathrm{~m} / \mathrm{s}, C_{\mathrm{D}}$ as a function of $U$ was curve-fitted with power function (Fig. 6). The curves for seven conifers studied previously in a wind tunnel experiment ${ }^{3}$ are shown in Fig. 6 . The average $C_{\mathrm{D}}$ of poplar crowns was found to be smaller than that of western hemlock, which had the smallest value among those for conifers. The results suggested that the wind permeability of poplar crowns is larger than conifer crowns due to the difference in flexibility of a leaf. The average extrapolated value of $C_{\mathrm{D}}$ at $30 \mathrm{~m} / \mathrm{s}$ was 0.102 ; This value can be used for estimating wind velocity that induce wind damage to poplar trees. 


\section{Effect of leaves on $C_{\mathrm{D}}$}

$C_{\mathrm{D}}$ in the defoliation season was smaller than that in the leaved season, because the same crown areas were used for the calculation. The average $C_{\mathrm{D}}$ of defoliated crowns at $10 \mathrm{~m} / \mathrm{s}$ was 0.133 (Fig. 7). The change in the crown area with the wind velocity variation would be small in the defoliation season because the swaying movement of the defoliated branches would be small. In fact, the decrease in $C_{\mathrm{D}}$ with an increase in the wind velocity was small for tree nos.1 and 2, as shown in Fig. 7. The ratio of $C_{\mathrm{D}}$ of defoliated crowns to that of leaved crowns increased with the wind velocity. The ratio at a wind velocity of $10 \mathrm{~m} / \mathrm{s}$ was in the range of 0.553 to 0.770 .

\section{Conclusions}

1. Drag coefficients of poplar crowns were successfully evaluated by a field test method in which the wind velocity and stem deflection were monitored simultaneously.

2. The drag coefficient decreased with an increase in the wind velocity.

3. The drag coefficient of poplar crowns was smaller than that of conifers studied in previous wind tunnel experiments.

4. The drag coefficient of defoliated crowns was smaller than that of leaved crowns.

\section{Acknowledgements}

This study was supported in part by JSPS KAKENHI (21580169). 


\section{References}

1. Kamimura K, Shiraishi N (2007) A review of strategies for wind damage assessment in Japanese forests. J For Res 12: 162-176

2. Hirata T (1953) Fundamental studies on the formation of cutting series (2) (in Japanese). Bull Tokyo Univ Forests 45: 67-88

3. Mayhead GJ (1973) Some drag coefficients for British forest trees derived from wind tunnel studies. Agr Meteorol 12: 123-130

4. Johnson RC, Ramey GE, O'Hagan DS (1982) Wind induced forces on trees. J Fluid Eng 104: $25-30$

5. Murakami S, Deguchi K, Takahashi T (1984) Shelter effects of trees as wind-breaks (In Japanese). Proceedings of Symposium on Wind Engineering, Tokyo, pp 129-136

6. Ishikawa H (2005) Experimental study on flow characteristics of trees (In Japanese). Nagare 24:483-490

7. Yamamoto R (1979) Protection of fruit trees against the strong wind damage (In Japanese). J Agricultural Meteorology 35: 177-187

8. Koizumi A, Ueda K (1986) Estimation of the mechanical properties of standing trees by bending test (1) (In Japanese). Mokuzai Gakkaishi 32: 669-676 


\section{Figure legends}

Fig. 1 Field test method for monitoring wind velocity and stem deflections

Fig. 2 Photographs and binarized images of crowns of sample trees (Left: no.1, center: no.2, right: no.3)

Fig. 3 An example of the time-series fluctuations for wind velocity $(U)$ and stem deflections $(\delta)$

Fig. 4 Relationship between drag coefficient $\left(C_{\mathrm{D}}\right)$ and wind velocity $(U)$

Fig. 5 Average and standard deviations in $C_{\mathrm{D}}$ calculated by generating moving averages from 1 to $10 \mathrm{~s}$

Fig. 6 Comparison between $C_{\mathrm{D}}$ values of poplars and conifers obtained from a wind tunnel study

${ }^{\text {a }}$ Reported by Mayhead ${ }^{3}$

${ }^{\mathrm{b}}$ No.1: $Y=1.77 X^{-0.911}$, no. $2: Y=1.14 X^{-0.824}$, no. $3: Y=1.79 X^{-0.714}$

Fig. 7 Relationship between wind velocity $(U)$ and drag coefficient $\left(C_{\mathrm{D}}\right)$ for defoliated crowns and $C_{\mathrm{D}}$ ratio (defoliated/leaved) 


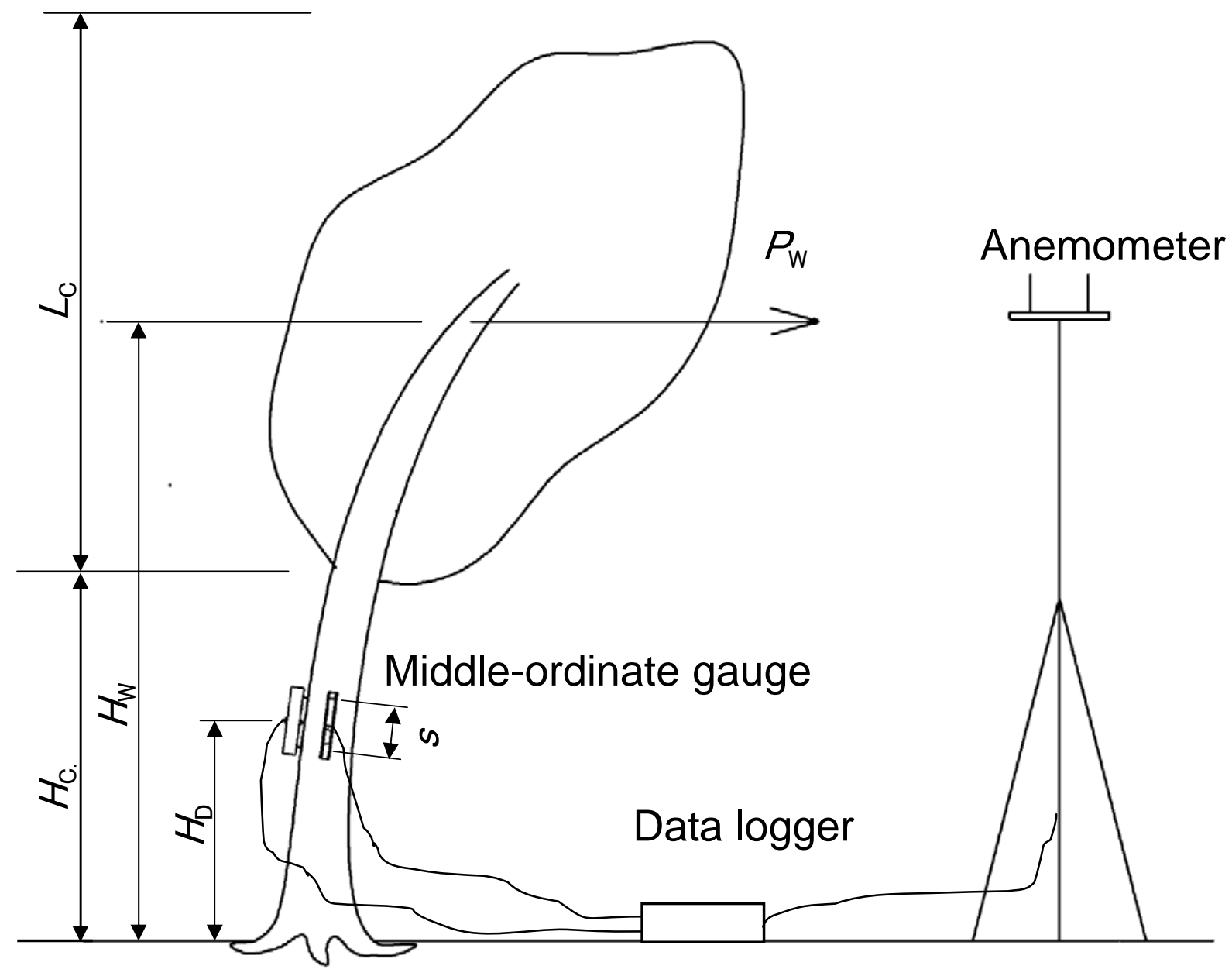

Fig. 1 Field test method for monitoring wind velocity and stem deflections 

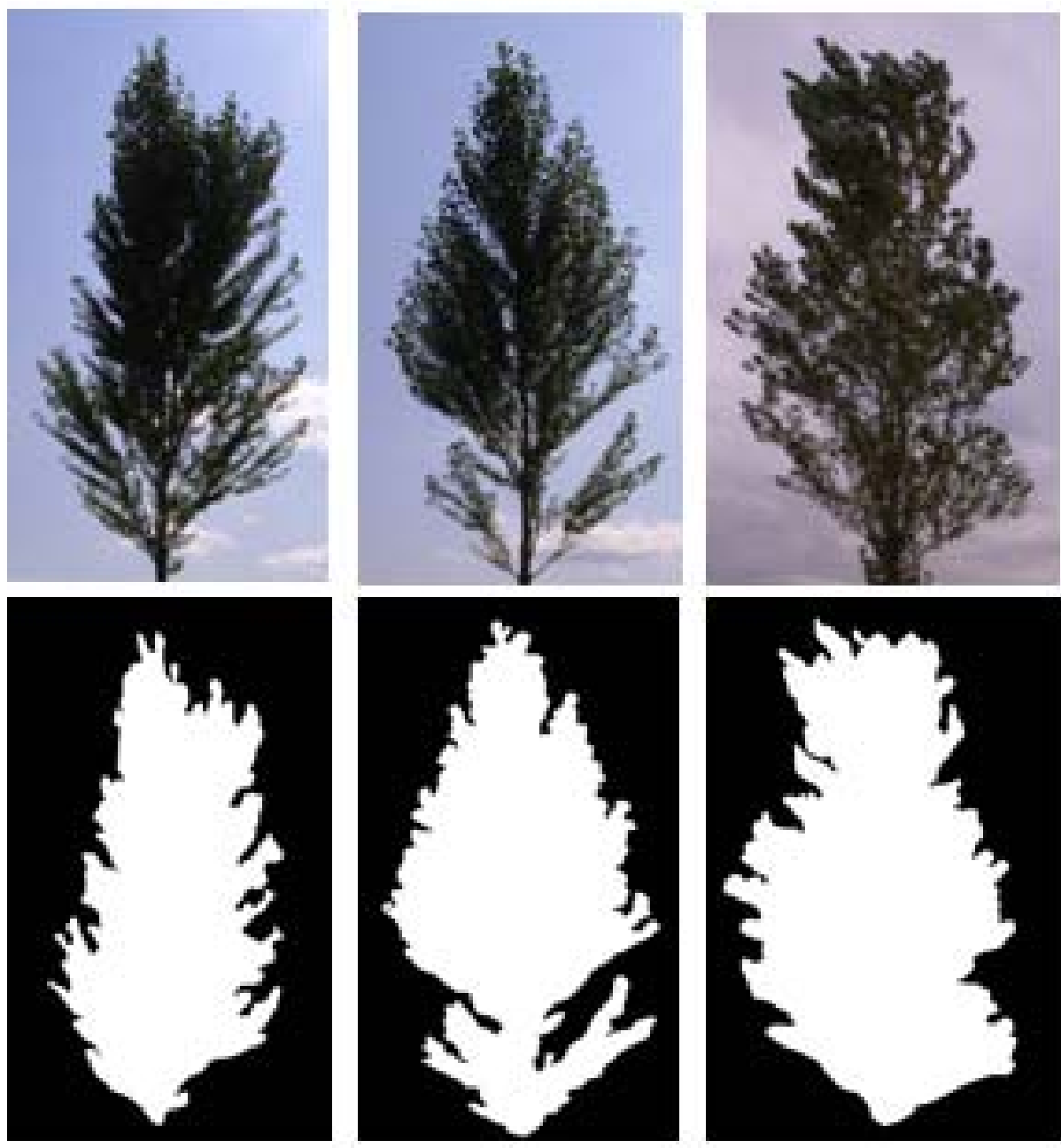

Fig. 2 Photographs and binarized images of crowns of sample trees (Left: no.1, center: no.2, right: no.3) 


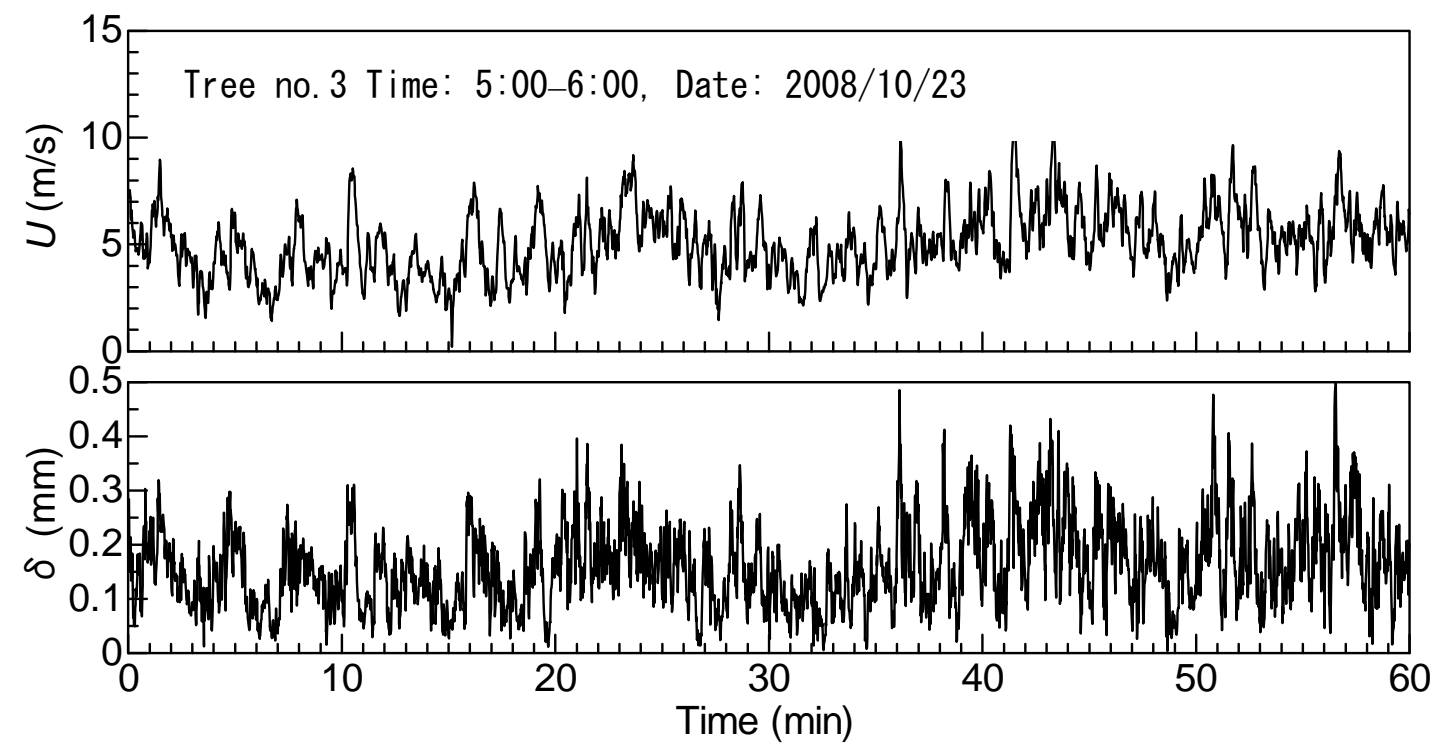

Fig. 3 An example of the time-series fluctuations for wind velocity $(U)$ and stem deflections $(\delta)$ 


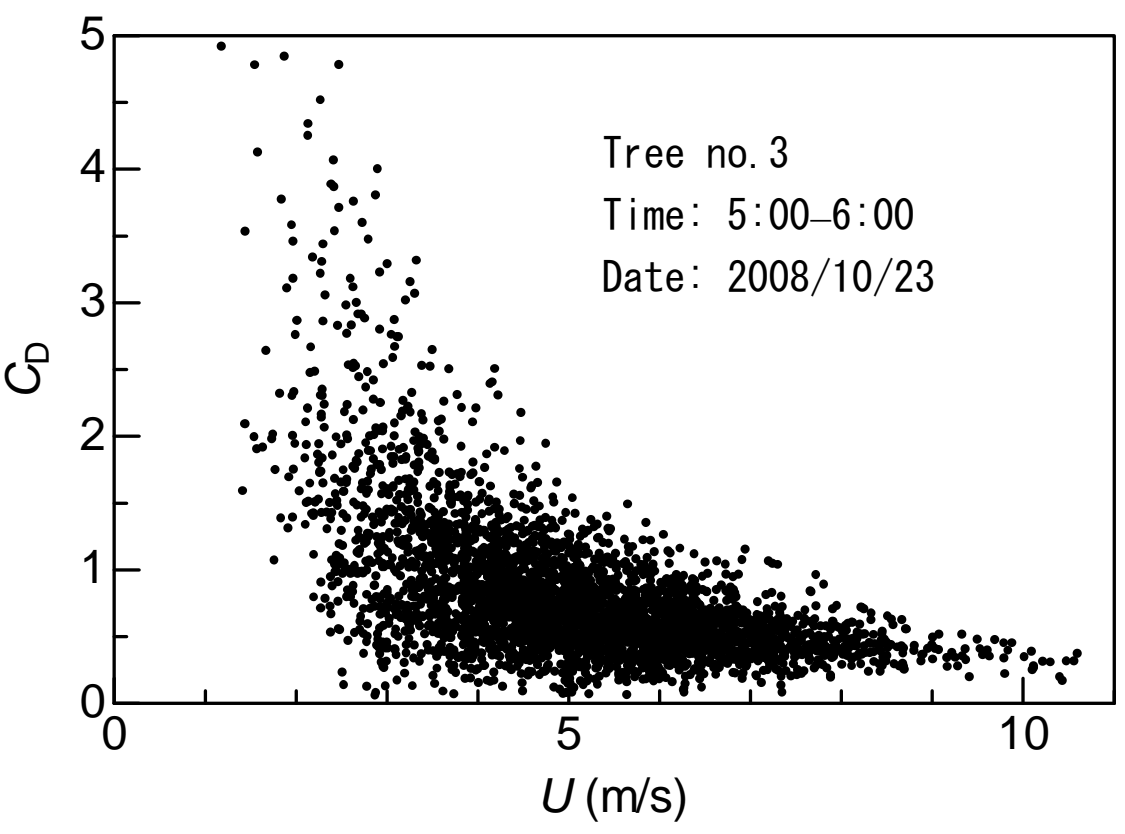

Fig. 4 Relationship between drag coefficient $\left(C_{\mathrm{D}}\right)$ and wind velocity $(U)$ 


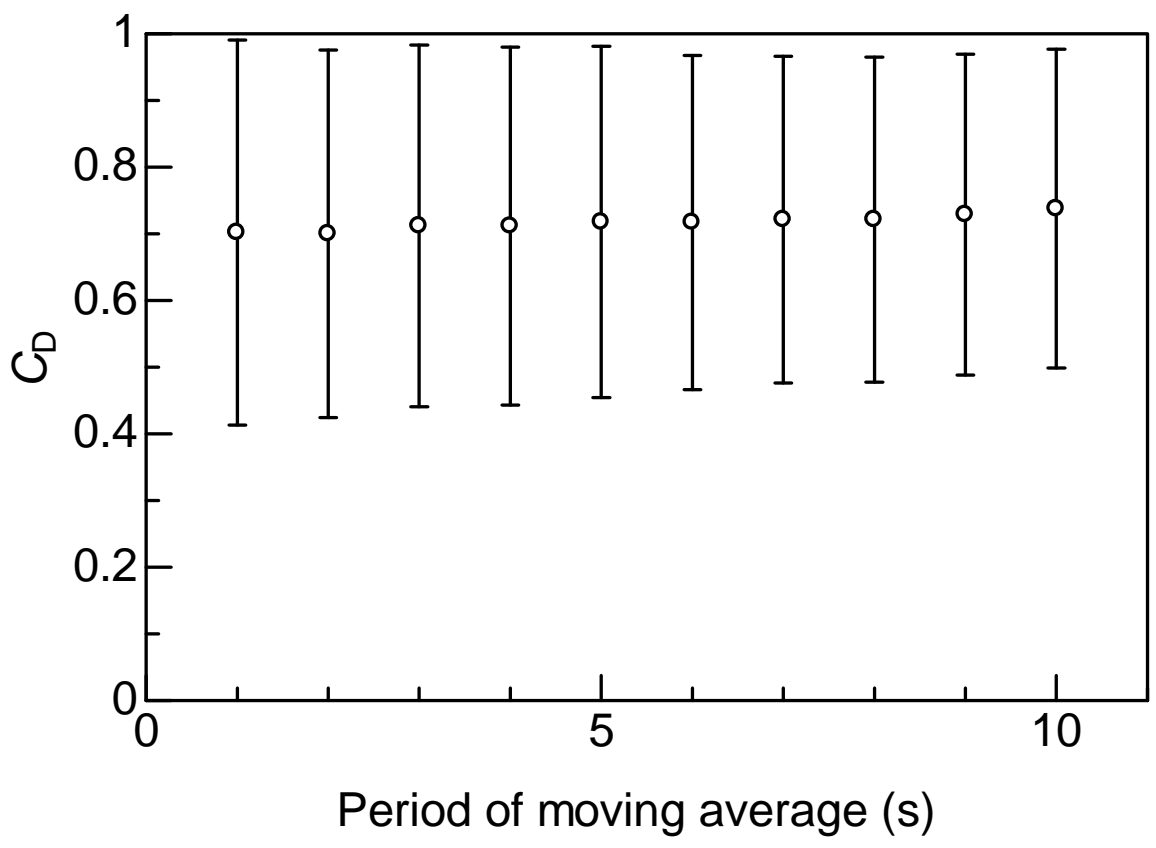

Fig. 5 Average and standard deviations in $C_{\mathrm{D}}$ calculated by generating moving averages from 1 to $10 \mathrm{~s}$ 


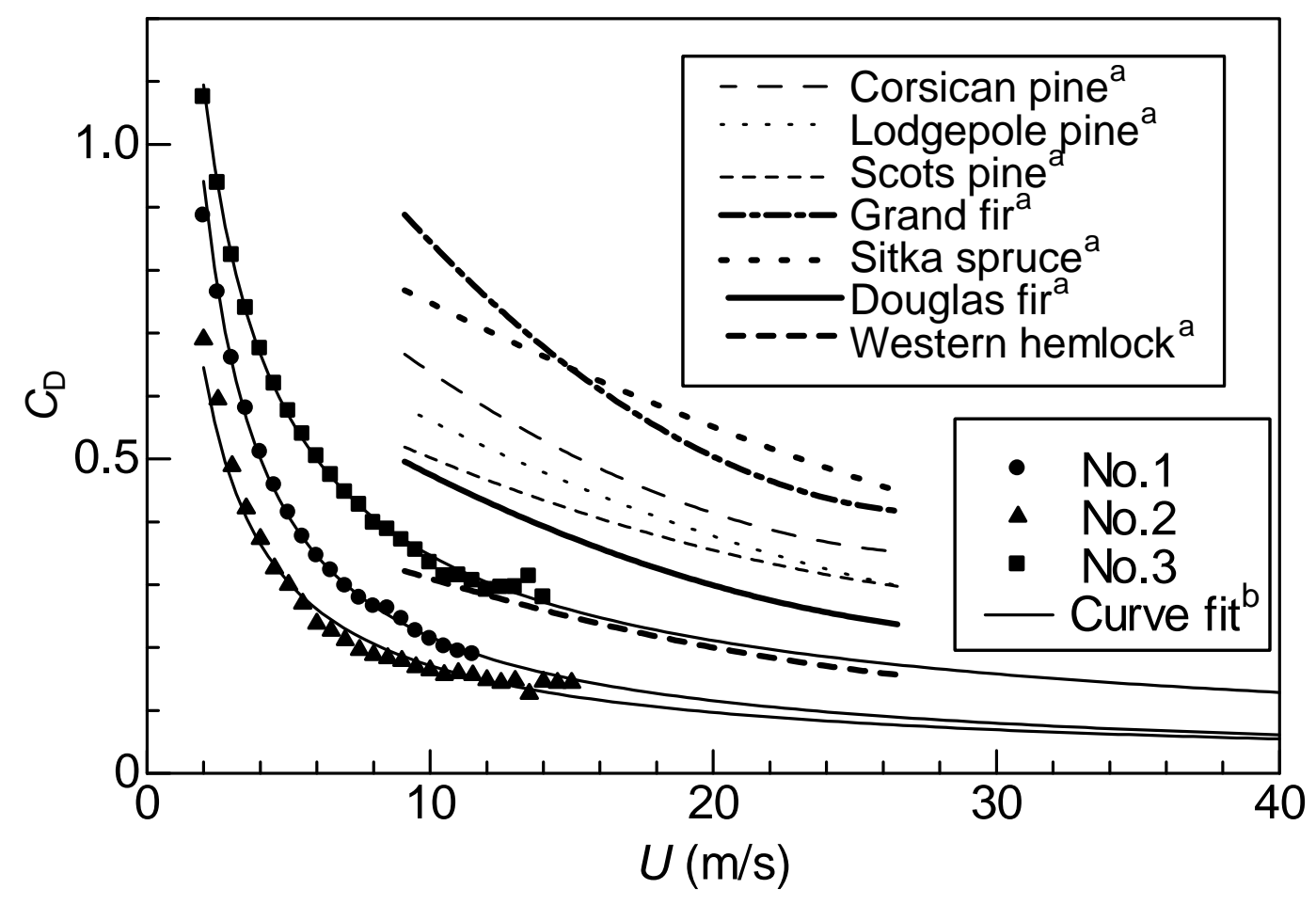

Fig. 6 Comparison between $C_{\mathrm{D}}$ values of poplars and conifers obtained from a wind tunnel study

${ }^{\text {a }}$ Reported by Mayhead ${ }^{3}$

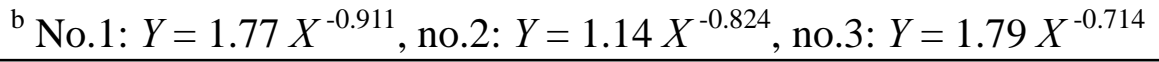




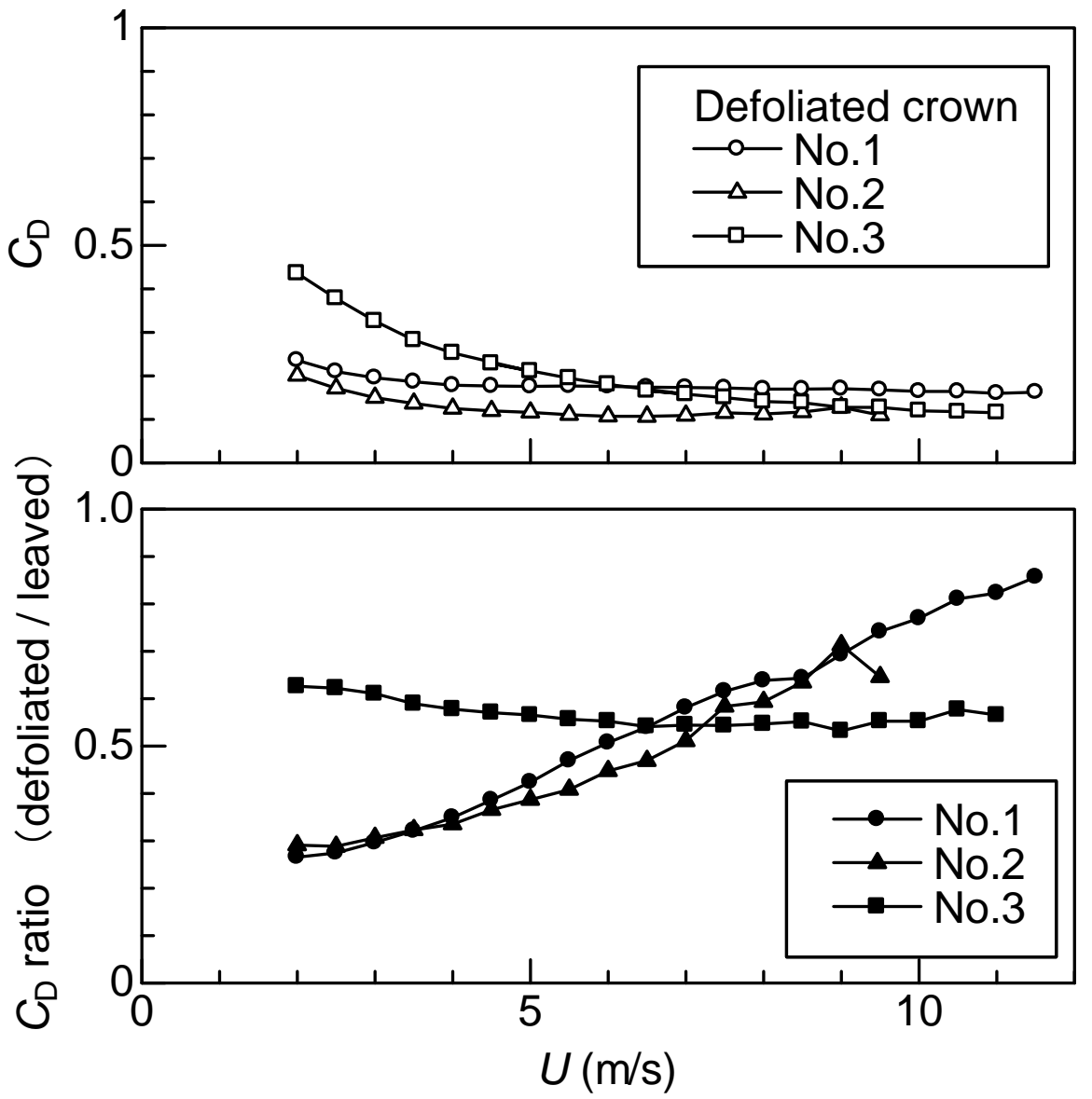

Fig. 7 Relationship between wind velocity $(U)$ and drag coefficient $\left(C_{\mathrm{D}}\right)$ for defoliated crowns and $C_{\mathrm{D}}$ ratio (defoliated/leaved) 
Table 1. Dimensions of sample trees

\begin{tabular}{ccccccc}
\hline No. & $H(\mathrm{~m})$ & $D_{\mathrm{B}}(\mathrm{cm})$ & $L_{\mathrm{C}}(\mathrm{m})$ & $B_{\mathrm{C}}(\mathrm{m})$ & $A\left(\mathrm{~m}^{2}\right)$ & $H_{\mathrm{W}}(\mathrm{m})$ \\
\hline 1 & 13.1 & 24.2 & 9.3 & 4.4 & 32.5 & 8.4 \\
2 & 12.3 & 19.3 & 7.8 & 3.6 & 22.0 & 8.4 \\
3 & 12.9 & 24.1 & 8.9 & 4.1 & 29.0 & 8.5 \\
\hline
\end{tabular}

$H$, Tree height; $D_{\mathrm{B}}$, Breast-height diameter; $L_{\mathrm{C}}$, Crown length;

$B_{\mathrm{C}}$, Crown breadth (east-west direction);

$A$, Horizontal projected area of crown assuming an ellipsoidal crown (east-west direction);

$H_{\mathrm{W}}$, Height of wind pressure center 
Table 2. Measurement periods for wind velocity and stem deflections

\begin{tabular}{cllrr}
\hline Tree no. & Leaf condition & $\begin{array}{c}\text { Measurement } \\
\text { period }\end{array}$ & $\begin{array}{c}\text { Measurement } \\
\text { time } \\
\text { (h) }\end{array}$ & \multicolumn{2}{c}{$\begin{array}{c}\text { Analysis time } \\
\text { (h) }\end{array}$} \\
\hline 1 & Leaved & Oct. 2007 & 232 & 82 \\
& Defoliated & Apr. 2008 & 120 & 59 \\
2 & Leaved & Oct. 2007 & 235 & 58 \\
& Defoliated & Apr. 2008 & 117 & 31 \\
3 & Leaved & Oct. 2008 & 402 & 115 \\
& Defoliated & Apr. 2008 & 48 & 44 \\
\hline
\end{tabular}

${ }^{\mathrm{a}}$ Data for wind velocities above $5 \mathrm{~m} / \mathrm{s}$ were included. 